\title{
A CONTRIBUIÇÃO DA BRINQUEDOTECA PARA O DESENVOLVIMENTO DA CRIANÇA NA EDUCAÇÃO INFANTIL
}

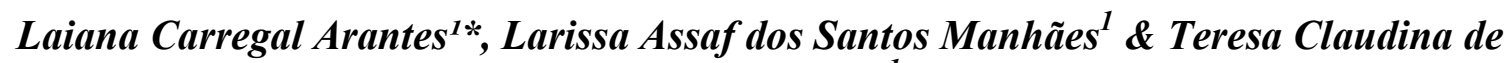 \\ Oliveira Cunha ${ }^{1}$
}

\begin{abstract}
RESUMO
ARANTES, L.C.; MANHÃES, L.A.S. B.; CUNHA, T.C.O. A contribuição da brinquedoteca para o desenvolvimento da criança na educação infantil. Perspectivas Online: Humanas \& Sociais Aplicadas, v.11, n.30, p.1-16, 2021.

$\mathrm{O}$ artigo dedicou-se ao tema brinquedoteca e sua importante contribuição no processo de ensino e aprendizagem na fase da educação infantil. O objetivo principal da pesquisa foi o de compreender a relevância do uso da brinquedoteca para o desenvolvimento da criança. A população da pesquisa envolveu 91 (noventa e um) professores que atuam na educação infantil da rede de ensino pública e privada do município de Campos dos Goytacazes, RJ. Trata-se de uma pesquisa qualitativa, de

natureza exploratória e descritiva. Para a coleta de dados utilizou-se de questionários por meio da plataforma online surveymonkey. A pesquisa apresenta a importância da brinquedoteca, enquanto recurso pedagógico, que favorece e possibilita o melhor e mais prazeroso desenvolvimento da criança. Os resultados revelam benefícios que a brinquedoteca proporciona para o desenvolvimento das habilidades sociais, emocionais e cognitivas da criança.
\end{abstract}

Palavras-chave: Educação Infantil; brinquedoteca; ludicidade; desenvolvimento infantil. 


\section{THE CONTRIBUTION OF A TOY LIBRARY TO THE CHILD DEVELOPMENT IN THE CHILDHOOD EDUCATION}

\begin{abstract}
This article has been dedicated to the subject of toy libraries and their important contribution to the process of the teaching and learning in the child education phase. The primary objective of this research was comprehending the relevancy of the use of toy libraries for the development of children. This research's populace involved 91 (ninety one) professors working in child education in the public and private networks in the municipality of

qualitative research, of an exploratory and descriptive nature. For data collection, this research used questionnaires through the online surveymonkey platform. This research showcases the importance of the toy library, as a pedagogic resource, which favors and enables a better and more pleasant child development. The results elucidate the benefits that toy libraries provide for the development of a child's social, emotional and cognitive abilities.
\end{abstract} Campos dos Goytacazes, RJ. This is a

Keywords: BNCC (National Curricular Database), to play, playfulness, child development.

\footnotetext{
${ }^{1}$ Institutos Superiores de Ensino do CENSA - ISECENSA - Laboratório de Formação de Professores - LAFORP NUPED/ISECENSA - Rua Salvador Correa, 139, Centro, Campos dos Goytacazes, RJ, CEP: 28035-310, Brasil. (*) e-mail: laianaarantes_campos@hotmail.com Data de recebimento: 23/01/2021. Aceito para publicação: 10/03/2021. Data da publicação: 14/04/2021.
}

Persp. Online: hum \& sociais aplicada., Campos dos Goytacazes, 30 (11)1-16- 2021 seer.perspectivasonline.com.br 


\title{
1. INTRODUÇÃO
}

Em seu artigo 29, a Lei de Diretrizes e Bases da Educação Nacional - LDB (BRASIL,1996) assinala que a educação infantil representa a primeira etapa da educação básica e deve ser oferecida em creches e pré-escolas, com a finalidade de promover o desenvolvimento integral da criança de 0 a 5 anos, portanto, envolve os fatores físico, psicológico, intelectual e social.

A começar da Educação Infantil, as crianças têm contato com as história e fábulas, como determinado na Base Nacional Comum Curricular - BNCC (BRASIL, 2018), as crianças aprendem a manejar os livros e até antes de ler já começam a interpretar histórias pelas imagens representadas em seus livros, além de já serem capazes de interpretar as palavras das imagens e a direção da escrita. Nota-se nesse último exemplo citado, que mesmo sem saberem ler, as crianças colocam seus dedos sobre as palavras correndo por todo o texto na direção correta de leitura.

De acordo com BNCC (BRASIL, 2018, p. 38), a vivência lúdica é direito da criança. É importante esse momento de descobrimento, convivência e imaginação, para o crescimento da criança em diferentes áreas do conhecimento.

\begin{abstract}
Brincar - cotidianamente de diversas formas, em diferentes espaços e tempos, com diferentes parceiros (crianças e adultos), ampliando e diversificando seu acesso a produções culturais, seus conhecimentos, sua imaginação, sua criatividade, suas experiências emocionais, corporais, sensoriais, expressivas, cognitivas, sociais e relacionais.
\end{abstract}

Assim, observa-se essa primeira etapa no desenvolvimento da criança como primordial para o seu amadurecimento social e cognitivo e também como incentivo a responder suas curiosidades e inquietações, desta forma, como apontam as nas Diretrizes Curriculares Nacionais Gerais para a Educação Básica (2010).

A prática da brincadeira proporciona o desenvolvimento do indivíduo, uma vez que colabora para a edificação do raciocínio, da independência e da imaginação, marcando um vínculo entre o brincar com o método de desenvolvimento.

\footnotetext{
Quando brinca de médico, por exemplo, após ter tomado uma injeção ou ter sido submetida a uma cirurgia, na brincadeira, passa do papel passivo para o ativo, reorganiza pensamentos e emoções; expressa desejos, fantasias, vontades e conflitos; exercita potencialidades, desenvolve a sociabilidade e a sensibilidade e se desenvolve intelectual, social e emocionalmente (MALUF, 2014 apud MORAES, 2020, p. 5).
}

O brincar ajuda também a criança entender e obedecer a regras, tanto em grupo, quanto individual, contribuindo para a integração do indivíduo na sociedade. Vygotsky (2007) assinala que, por meio do brincar, deve-se estimular que sentimentos sejam partilhados, favorecendo à criança percebê-los, aceitá-los e demonstrá-los.

Froede et al. (2014) afirmam que o brincar é muito importante para o do desenvolvimento do indivíduo, facilitando a comunicação e as interações sociais,

Persp. Online: hum \& sociais aplicada., Campos dos Goytacazes, 30 (11)1-16- 2021

seer.perspectivasonline.com.br 
compreendem que por meio das brincadeiras a criança pode expressar suas dificuldades, seus sentimentos e suas fantasias.

Bomtempo et al. (2016 apud MORAES, 2020, p. 6) afirmam que "a criança impossibilitada de brincar tem seu desenvolvimento comprometido e seu equilíbrio emocional perturbado". Pode-se compreender que o uso da ludicidade, por meio de jogos e brincadeiras, é importante para o desenvolvimento da criança, tanto na escola quanto no seu desenvolvimento emocional, social e afetivo.

A brinquedoteca para Maluf (2007) representa um lugar de grande estímulo para criança. A definição da palavra brinquedoteca em sua origem, quer dizer, "lugar de brinquedo: 'teca' vem do sufixo grego theke, que significa cofre, caixa, depósito, sendo utilizado para fazer referência ao local onde se guarda algo" (FORTUNA, 2011, p.163).

A brinquedoteca é um espaço que harmoniza, por meio da atividade lúdica, possibilitando à criança a construção e composição do pensamento social e emocional. Sendo assim, é um espaço de percepção da existência, em que as crianças trocam experiências e interagem com o desconhecido, evidenciando a sua experiência e entendendo as das outras. Compreende-se a brinquedoteca como um local de grande crescimento pessoal para a criança, não sendo apenas um lugar bonito para se guardar brinquedos, e sim um espaço que promove o brincar com essência. Dessa forma "[...] a ação de brincar que faz um objeto ser brinquedo" (FORTUNA, 2011, p.163).

Noffs (2016) ressalta que para que a brinquedoteca proporcione situações em que crianças possam brincar livremente com suas fantasias, não é preciso muito. Para a autora, objetos simples podem compor esse espaço de forma criativa e enriquecedora, materiais novos ou usados, brinquedos atuais ou antigos, de madeira, pano, que oportunizam seu uso de maneira independente, fomentando a criança a liberar sua criatividade e suas idealizações, nesse ambiente notadamente lúdico.

Nesse contexto, a brinquedoteca nasce na sociedade com a proposta de possibilitar a criança um espaço para brincar e implementar seus "faz de conta" (BUENO; FRAGA; 2012).

Santos (2000) afirma que o brincar e os brinquedos têm grande importância para o desenvolvimento humano, na medida em que gera a possibilidade de estudar a relação da criança com o mundo externo.

Souza e Damasceno (2012) ressaltam que muitas escolas já possuem a brinquedoteca em seu ambiente escolar e a utilizam como um recurso pedagógico, para a socialização e evolução das crianças. O professor pode observar seu aluno e ajudá-lo futuramente por meio de suas verificações, visto que a criança se revela em suas brincadeiras. Para os autores o espaço vem sendo considerado

como um meio essencial para a construção da aprendizagem pelas crianças, não sendo este um lugar para brincar desorganizado, de qualquer forma, um lugar para os (as) professores (as) soltarem as crianças e terem um descanso, mas um lugar onde possa servir para ensinar as crianças através das brincadeiras, pelo lúdico, um meio de atrair esse ser tão ativo, agitado, curioso para descobrir o mundo, por meio de brincadeiras orientadas com um objetivo de ensinar, de possibilitar conhecimento (SOUSA; DAMASCENO, 2012, p. 2).

Persp. Online: hum \& sociais aplicada., Campos dos Goytacazes, 30 (11)1-16- 2021 
A brinquedoteca deve ser vista pelo professor como um local de aprendizagem e deve ser preparado e planejado para que surta efeito no desenvolvimento da criança, e não apenas como um local só para se distrair. Santos $(1995$, p. 39) afirma que:

O profissional educador, jamais deve utilizar o jogo apenas como caráter lúdico, dessa forma não haverá contribuição para a aprendizagem. Os jogos e as brincadeiras devem ser muito bem planejados e escolhidos para que haja estímulo e construção do novo conhecimento.

\subsection{Ludicidade}

No ambiente da brinquedoteca busca-se, por meio da diversidade de brinquedos e de atividades lúdicas, oportunizar o equilíbrio de necessidades que podem estar escondidas. Por meio da livre entonação, cuidado e momentos de compensação pela performance espontânea, o autoconceito é fortalecido (CUNHA, 2010).

O brincar faz com que a criança crie situações imaginárias e isso é fundamental para o seu desenvolvimento, pois é a partir do brincar que ela aprende a como agir com o mundo. Na educação infantil o lúdico precisa ser reconhecido como uma forma de aprendizagem, na medida em que o uso de brincadeiras e o jogo é uma estratégia de ensino para desenvolver o ensino e aprendizagem.

Não existe nada mais motivador para qualquer criança do que aprender brincando, pois ela poderá explorar sua imaginação, seus desejos, possibilitando o descobrimento de si mesmo, de suas capacidades, descobrindo sobre o mundo a sua volta, estimulando por si só o seu senso crítico-reflexivo (LEMOS; MENEZES; ALVES, 2016, p. 3.).

De acordo com Base Nacional Comum Curricular (BRASIL, 2018, p. 38), a vivência lúdica é direito da criança. É importante esse momento de descobrimento, convivência e imaginação, para o crescimento da criança em diferentes áreas do conhecimento. De forma intencional, a brincadeira modifica e estende a aquisição do conhecimento pelas crianças. Assim sendo, professores devem elaborar propostas que envolvam o brincar em suas aulas/planejamentos, para que o aluno vivencie múltiplas sensações, emoções, conflitos, investigações, de modo a expandir seus conhecimentos (BRASIL, 2018).

Camargo (2011) ressalta que o brincar deve ser livre quando se busca o desenvolvimento pessoal da criança, porém ainda é notável muitos professores que interferem nesse meio de desenvolvimento da criança, limitando-a de diferentes formas; classificando quais brinquedos e brincadeiras podem brincar, impedindo-se de falar num tom mais elevado para não atrapalhar os outros, proibindo-a de explorar outros espaços ou até monitorando o local da brincadeira para que não fique "bagunçado". Peters (2009, p. 114-115) defende que, ao invés dessa ação, deveriam "observar o que se passa durante a brincadeira das crianças para buscar temas e reflexões que contribuiriam para estas atividades", aproveitando esse momento para, de maneira pedagógica, notar o comportamento da criança em suas brincadeiras, como se relaciona com seus amigos, como manifesta suas emoções em dadas situações, de forma favorável a ajudar a criança, e jamais de maneira conforme presenciamos, no qual "institui-se uma brinquedoteca para as crianças brincarem, mas o brincar é desvalorizado".

Persp. Online: hum \& sociais aplicada., Campos dos Goytacazes, 30 (11)1-16- 2021

seer.perspectivasonline.com.br 
É necessário, portanto, desconstruir o pensamento de alguns pais e professores que ainda não dão importância para o brincar no dia a dia escolar. A brincadeira planejada é, sem dúvida, uma grande ferramenta pedagógica essencial para o crescimento cognitivo, motor e social de toda a criança.

A brinquedoteca apresenta-se como um recurso pedagógico que oportuniza ao professor a percepção da criança em todos o processo de desenvolvimento de habilidades sociais, cognitivas e afetivas. Dentro desse contexto, este estudo tem como objetivo principal apresentar e analisar a relevância do uso da brinquedoteca para $\mathrm{o}$ desenvolvimento da criança na educação infantil.

\section{METODOLOGIA}

Este estudo tem um enfoque qualitativo de caráter descritivo, considerando a busca pelo conhecimento e o despertar ações a favor de um objetivo, e no caso desse estudo, o desenvolvimento do aluno no espaço da brinquedoteca (MINAYO, 2001 apud PRODANOV, FREITAS, 2013, p.14).

A pesquisa parte de um estudo bibliográfico sobre o tema principal. Fonseca (2002, p. 32) esclarece que a importância da revisão de literatura, pois ela é construída a partir de opiniões teóricas já analisadas e divulgadas por meio de artigos e livros. Utilizaram-se também documentos oficiais, tais como a Base Nacional Comum Curricular (BRASIL, 2018) e a Lei de Diretrizes e Bases da Educação Nacional (BRASIL,1996).

Quanto aos objetivos, a pesquisa caracteriza-se por ser exploratória e descritiva, o que possibilitou uma nova compreensão sobre a temática trabalhada. Segundo Gil (2010, p. 28) a realização de uma pesquisa é essencial pois "aprofunda o conhecimento da realidade porque explica a razão, o porquê das coisas". Nesse estudo, pode-se compreender, fundamentalmente, a finalidade e os benefícios que o espaço da brinquedoteca favorece na aprendizagem da criança. Quanto ao caráter descritivo, pode-se evidenciar as propriedades de determinada situação ou área e define sua natureza, como ocorre no presente trabalho (VERGARA, 2000).

Quanto aos instrumentos para a coleta de dados, optou-se da aplicação de questionários online junto a professores que atuam na Educação Infantil no município de Campos dos Goytacazes, RJ. Participaram da pesquisa 91 (noventa e um) professores, distribuídos entre a rede privada e pública de ensino.

\section{RESULTADOS E DISCUSSÃO}

Esta etapa da pesquisa busca apresentar os resultados e análise dos dados coletados e compreender a relevância do uso da brinquedoteca para o desenvolvimento da criança na educação infantil.

A população da pesquisa foi composta de professores que atuam na educação infantil no município de Campos dos Goytacazes, com uma amostra (respondentes) de 91 professores, subdivididos em $53 \%(\mathrm{~N}=48)$ que atuam exclusivamente na rede privada de ensino, $39 \%(\mathrm{~N}=36)$ na rede pública e $8 \%(\mathrm{~N}=7)$ que atuam concomitantemente na rede privada e pública. (Figura 1)

Persp. Online: hum \& sociais aplicada., Campos dos Goytacazes, 30 (11)1-16- 2021 seer.perspectivasonline.com.br 


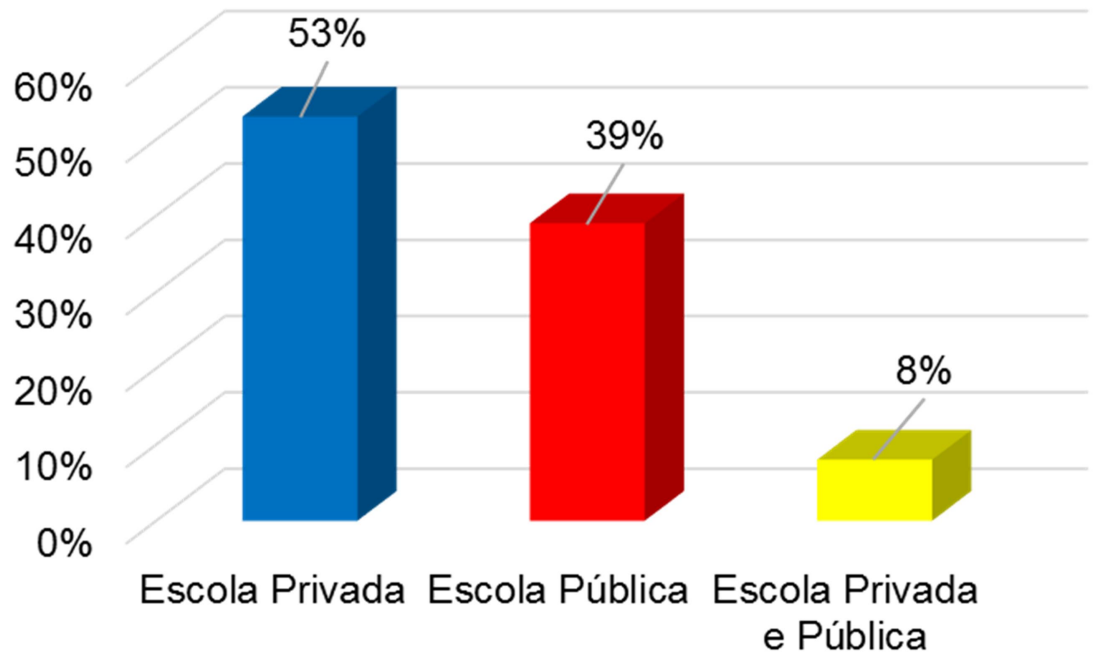

Figura 1: Distribuição dos professores, atuação docente Fonte: Pesquisa de campo/Elaboração própria.

Considerando o objeto de estudo, buscou-se identificar junto aos participantes a importância do brincar para a aprendizagem da criança. A pesquisa revela a compreensão dos professores sobre a questão, destacando-se os depoimentos, a seguir, como os mais representativos:

"A aprendizagem vem do prazer, e o brincar alia ambos. Brincando a criança constrói regras e aprende a segui-las. Além de aprender conteúdos de forma lúdica" (Depoimento professor).

"A brincadeira é uma das maneiras mais espontânea da criança manifestar seus medos, suas dúvidas, seus anseios, seu aprendizado" (Depoimento professor).

"Ao brincar a criança recria o mundo demonstrando como vê e reage a vida em sociedade" (Depoimento professor).

"Brincando as crianças desenvolvem habilidades essenciais para a vida, estimula suas inteligências, aguça a curiosidade e favorece $o$ autoconhecimento" (Depoimento professor).

"Desenvolve a criança em vários aspectos: cognitivo, afetivo e social" (Depoimento professor).

"Na educação infantil o brincar é um fator imprescindível para o desenvolvimento da criança, atendendo as diversas áreas para a inserção da aprendizagem" (Depoimento professor).

"No ato de brincar que a criança demonstra sua afetividade, equilibro emocional além de desenvolver diversas habilidades fundamentais na primeira infância.' (Depoimento professor).

"O brincar é natural da criança, através dele ela representa situações do cotidiano, resolve conflitos internos, socializa, interage e absorve conceitos necessários de forma leve e lúdica" (Depoimento professor).

Persp. Online: hum \& sociais aplicada., Campos dos Goytacazes, 30 (11)1-16- 2021 
"O brincar na educação infantil é de suma importância para a aprendizagem, tornando-a significativa e eficaz" (Depoimento professor).

"Sim, as brincadeiras podem trabalhar na aceitação do perder e ganhar, ajudar o próximo, também pode trabalhar no desenvolvimento na matemática caso seja uma brincadeira que envolva números" (Depoimento professor).

Segundo Sommerhalder e Alves (2011, p. 21), "brincar é fundamental para a criança na medida em que possibilita que ela se desenvolva, ou melhor, que se constitua como humano".

Dando continuidade à análise, perguntou-se aos respondentes se na escola em que atuam, existe uma brinquedoteca ou algum outro espaço, que tem funções semelhantes à de uma brinquedoteca. 65\% $(\mathrm{N}=59)$ dos professores afirmaram que sim, 29\% $(\mathrm{N}=26)$ disseram que não. A pequis arvela ainda que para $7 \%(\mathrm{~N}=6)$ dos professores a escola não possui uma brinquedoteca pois para a gestão da escola a sala de aula é um espaço lúdico e suficiente.

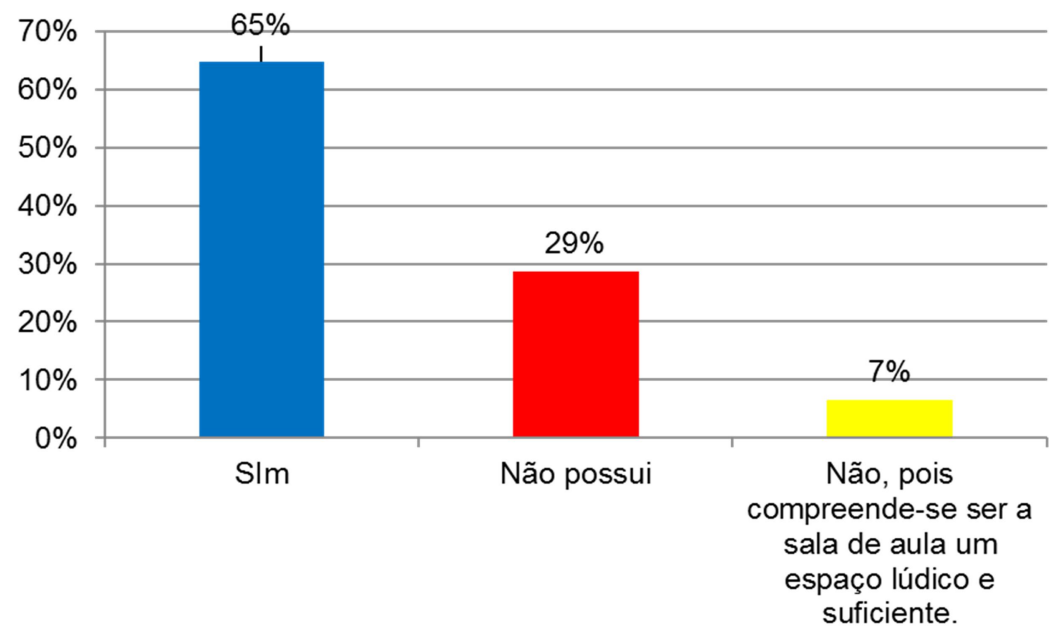

Figura 2: A Escola possui brinquedoteca?

Fonte: Pesquisa de campo/Elaboração própria.

Aqueles que afirmaram ter uma brinquedoteca ou um lugar similar a ela na instituição em que atuam, acrescentaram a suas respostas o nome que esse espaço recebe: Sala da imaginação; Espaço Literarte; Biblioteca Infantil; Sala Maker; Sala de Psicomotricidade; Sala de Jogos.

Buscando responder aos objetivos desse trabalho, perguntou-se aos professores o que significa uma brinquedoteca. Evidenciam-se as respostas que mais expressam esse significado, de acordo com a finalidade desse ambiente.

"Consiste em um espaço lúdico voltado para as crianças com livros e brinquedos que visam estimular o processo ensino aprendizagem dos alunos" (Depoimento professor).

Persp. Online: hum \& sociais aplicada., Campos dos Goytacazes, 30 (11)1-16- 2021 
"É um espaço específico e rico em materiais e instrumentos para desenvolver a ludicidade, a imaginação, a criatividade e as múltiplas habilidades das crianças" (Depoimento professor).

"Espaço em que a criança pode expressar-se livremente, desenvolver a sua criatividade, imaginação, senso de responsabilidade, valores, criticidade, autonomia, oralidade, entre outros. Além de que tal espaço permite ao educador fazer uma análise reflexiva e observatórios de cada aluno e a sua relação e interação com o meio e com os objetos" (Depoimento professor).

"Local onde existe a possibilidade da evolução mental, psicológico, social e físico da criança por meio lúdico. Tem como principal função desenvolver e estimular raciocínio lógico, coordenação motora etc." (Depoimento professor).

"Lugar com brinquedos e jogos com finalidades pedagógicas, para auxiliar no processo de desenvolvimento de ensino" (Depoimento professor).

"Significa um espaço com o objetivo de despertar de forma lúdica a aprendizagem. Insere-se neste ambiente objetos que desenvolvam a leitura, o imaginário e a criatividade através do corpo, da fala e do brincar com a mediação de um profissional" (Depoimento professor).

"Um espaço empírico, criativo, fomentador de ideias e realizações" (Depoimento professor).

"Um espaço lúdico onde a criança pode construir, criar e desconstruir. Um espaço do brincar do faz de contas de ser quem ele não é. Um lugar específico para ludicidade" (Depoimento professor).

"Um espaço lúdico, onde a fantasia, a imaginação pode ser realidade" (Depoimento professor).

"Um espaço preparado com materiais que estimulem o brincar, o lúdico. Nesse lugar é possível explorar materiais diversos, experimentar, fantasiar, sentir..." (Depoimento professor).

"Um espaço próprio para os brinquedos. Acho importante destacar que não deve ser entendido como um "depósito" de brinquedos, mas um ambiente preparado e organizado de modo que as crianças possam se desenvolver por meio de tais instrumentos" (Depoimento professor).

"Um local onde a ludicidade será trabalhada, estimulando e desenvolvendo a aprendizagem significativa de cada educando, de acordo com sua faixa etária e com seu próprio ritmo" (Depoimento professor).

Sobre essa questão, Fortuna (2011, p. 163) assinala ser a brinquedoteca um local de grande crescimento pessoal para a criança, não sendo apenas um lugar bonito para se guardar brinquedos, e sim um espaço que promove o brincar com essência. Dessa forma "[...] a ação de brincar que faz um objeto ser brinquedo".

Persp. Online: hum \& sociais aplicada., Campos dos Goytacazes, 30 (11)1-16- 2021 
À importância da brinquedoteca em uma escola, a pesquisa revela que, de forma unânime, os professores compreendem ser de grande importância a brinquedoteca para o processo de aprendizagem da criança. Destacam-se algumas justificativas:

"Seria um sonho!!! A criança poderia brincar, aprender a se comunicar, liberar suas emoções (desejos e sentimentos), desenvolver sua criatividade, adquirir conhecimentos, desenvolver sua autoestima, se socializar num ambiente lúdico" (Depoimento professor).

"A brinquedoteca é importante para o desenvolvimento global da criança. Neste espaço, onde a ludicidade é explorada as crianças desenvolvem a imaginação e aprendem brincando" (Depoimento professor).

"Para que além dos momentos destinados ao brincar em sala de aula, o professor possa criar situações com outros tipos de recursos e espaços diferentes. Assim, a criança terá mais oportunidades de explorar e aprender brincando" (Depoimento professor).

"Pois entendo que a sala de aula não é suficiente para trabalhar o lúdico. Entendo ser necessário um espaço mais específico, com variadas propostas de brincadeiras e jogos" (Depoimento professor).

"Pois o brincar auxilia os processos de socialização, comunicação, expressão e construção do conhecimento" (Depoimento professor).

"Se torna um ambiente facilitador da aprendizagem estimulando a criança a criatividade" (Depoimento professor).

"Sim o brincar ajuda em todo desenvolvimento da criança, ela se expressa melhor, através do brincar a criança tem mais prazer em aprender e se desenvolve melhor" (Depoimento professor).

"Toda criança precisa brincar para desenvolver várias habilidades, superar desafios, socializar" (Depoimento professor).

"Um espeço dedicado a esses momentos proporciona uma rotina estruturada, com objetivos específicos capazes de facilitar o processo de aprendizagem" (Depoimento professor).

"Uma ferramenta indispensável ao professor e ao crescimento emocional e cognitivo ao aluno" (Depoimento professor).

A brinquedoteca é, portanto, fundamental na medida em que favorece "a construção do saber, em situações de prazer, com gosto de aventura, na busca pelo conhecimento espontâneo e prazeroso", e impulsiona as sensações, fundamentos e aprendizagens (CUNHA, 2001 apud LIMA; DELMONICO, 2010, s/p).

Silva et al. (2019) reforçam que a brinquedoteca é um lugar onde se mantem interações, seja com brinquedos e/ou com outras crianças, resgata a personalidade, o que é verdadeiro e autêntico na criança.

Quando perguntados sobre a frequência com que a Brinquedoteca é utilizada, $30 \%(\mathrm{~N}=26)$ dos respondentes afirmaram que é utilizada todos os dias, enquanto

Persp. Online: hum \& sociais aplicada., Campos dos Goytacazes, 30 (11)1-16- 2021

seer.perspectivasonline.com.br 
$70 \%(\mathrm{~N}=62)$ disseram não ser regular sua ida a esse local. A pesquisa apresenta as seguintes justificativas para o não uso frequente do espaço:

"Devido à quantidade de turmas, é feito um cronograma e as turmas frequentam semanalmente" (Depoimento professor).

"É utilizada de acordo com a necessidade do professor" (Depoimento professor).

"Ela fica disponível todos os dias, basta o professor pegar a chave na coordenação no momento que achar oportuno" (Depoimento professor).

"Em algum momento guiado por um professor e aberto a todo momento que o aluno estiver livre para entrar" (Depoimento professor).

"Existem os horários organizacionais, mas que também nos permite que exploremos fora deles" (Depoimento professor).

"Infelizmente, alguns professores não utilizam esse espaço" (Depoimento professor).

"Não contamos com brinquedoteca nas dependências da escola. Porém sempre desenvolvemos brincadeiras e jogos na sala, no pátio e/ou outros espaços" (Depoimento professor).

A seguir, a Tabela 1 revela o que as escolas possuem ou como é a parte física da brinquedoteca existente. A busca por essa informação (quais os itens mais comuns que compõem esse espaço e como ele é) apresentou-se como de relevância para a pesquisa, pois em função da pandemia vivenciada - escolas fechadas - não foi possível visitá-las e, portanto, conhecer como são estruturadas.

Tabela 1: Da organização e estrutura das brinquedotecas (Fonte: Pesquisa de campo/Elaboração própria).

\begin{tabular}{l|l|l|l|l|l}
\hline Questões & Sim & Não & Total \\
\hline ampla e arejada & $68 \%$ & 53 & $32 \%$ & 25 & 78 \\
\hline $\begin{array}{l}\text { possui um profissional que atua } \\
\text { exclusivamente no espaço }\end{array}$ & $49 \%$ & 40 & $51 \%$ & 41 & 81 \\
\hline $\begin{array}{l}\text { espaço é suficiente para acolher as } \\
\text { crianças de cada turma }\end{array}$ & $76 \%$ & 61 & $24 \%$ & 19 & 80 \\
\hline $\begin{array}{l}\text { possui mesas e cadeiras adequadas para a } \\
\text { idade }\end{array}$ & $59 \%$ & 47 & $41 \%$ & 33 & 80 \\
\hline $\begin{array}{l}\text { expositor de livros } \\
\text { jogos pedagógicos }\end{array}$ & $71 \%$ & 57 & $29 \%$ & 23 & 80 \\
\hline espelho & $72 \%$ & 58 & $28 \%$ & 23 & 81 \\
\hline $\begin{array}{l}\text { prateleiras para a organização dos } \\
\text { materiais }\end{array}$ & $48 \%$ & 38 & $53 \%$ & 42 & 80 \\
\hline fantoches & $78 \%$ & 62 & $23 \%$ & 18 & 80 \\
\hline fantasias para contação de histórias & $71 \%$ & 56 & $29 \%$ & 23 & 79 \\
\hline
\end{tabular}

Persp. Online: hum \& sociais aplicada., Campos dos Goytacazes, 30 (11)1-16- 2021 seer.perspectivasonline.com.br 
A Tabela 1 mostra com destaque que as brinquedotecas ou espaços semelhantes possuem em sua maioria um ambiente amplo e arejado, contudo $49 \%(\mathrm{~N}=51 \%)$ delas não possuem um profissional exclusivo que atue no espaço. Já a maior parte possui mesas e cadeiras adequadas para as crianças (59\%), com jogos, livros, fantoches e fantasias, organizados em prateleiras. Em metade delas (53\%), não há espelhos para serem usados em algumas atividades pedagógicas.

Sobre a questão organização e estrutura das brinquedotecas, Maluf (2007, p. 64) destaque "[...] sua organização depende do que cada uma delas se propõe, sem que nunca deixem de enfatizar a importância das brincadeiras no processo de aprendizagem e de desenvolvimento da criança".

Em seguida, perguntou-se aos respondentes sobre a influência brinquedoteca para o desenvolvimento da criança. Todos os professores compreendem ser a brinquedoteca um recurso pedagógico positivo. Destacam-se algumas respostas que representam as ideias centrais dos professores participantes da pesquisa:

"A brinquedoteca é importante no desenvolvimento da criança, pois o brincar desenvolve não só o raciocínio, mas a formação da criança em todas as áreas" (Depoimento professor).

"A ludicidade e o brincar fazem parte dos estímulos no processo de uma aprendizagem significativa" (Depoimento professor).

"Ela é um espaço no qual a criança tem a sua oralidade estimulada, a imaginação, a criatividade. A percepção visual, a identidade, é um ambiente excelente para o trabalho lúdico e afetivo" (Depoimento professor).

"O brincar é um eixo estruturante para a Educação Infantil, segundo a própria BNCC. É a partir dessa ação que devem partir os objetivos da aprendizagem, pois brincando a criança aprende de forma lúdica, interativa e significativa" (Depoimento professor).

Considerando o objeto de estudo, buscou-se identificar também junto aos participantes 03 (três) palavras-chave sobre a importância de uma brinquedoteca. A pesquisa revela a compreensão dos professores sobre a questão, destacando-se as palavras, a seguir: "Desenvolvimento", "Ludicidade" e "Aprendizagem".

O lúdico precisa estar presente na formação do indivíduo, seja ele de forma direcionada ou de forma espontânea, viver e conviver são fundamentais na construção de um ser humano, e tais habilidades são desenvolvidas, também, no brincar de uma criança com outra, onde ela aprende além de conteúdos ditos como "fundamentais", são habilidades para a vida (OLIVEIRA, 2011, p.120).

Segundo Kishimoto (1998 apud ROSA; KRAVCHYCHYN; VIEIRA, 2010, p. 18):

A brinquedoteca incentiva a autonomia e desenvolve a capacidade crítica e de escolha da criança, além de promover o trabalho em equipe, a socialização, o desenvolvimento infantil, a comunicação, a criatividade, a imaginação e o desenvolvimento de atividades lúdicas.

Persp. Online: hum \& sociais aplicada., Campos dos Goytacazes, 30 (11)1-16- 2021 seer.perspectivasonline.com.br 
Dando continuidade ao estudo, perguntou-se aos respondentes se planejam suas aulas para o desenvolvimento de atividades na brinquedoteca. $51 \%(\mathrm{~N}=59)$ dos professores afirmaram que sim, $43 \%(\mathrm{~N}=38)$ disseram que não.

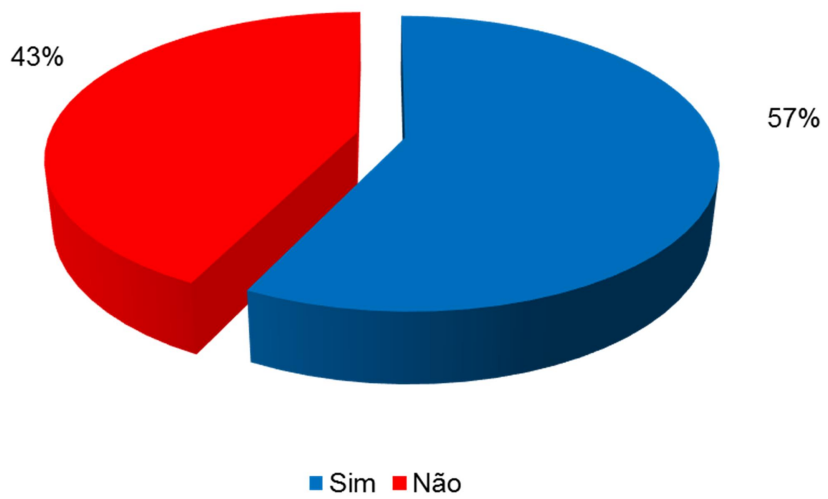

Figura 3: Quanto ao planejamento das aulas Fonte: Pesquisa de campo/Elaboração própria

A Figura 3 aponta que 43\% (N=3) dos professores respondentes não planejam suas aulas para o desenvolvimento de atividades na brinquedoteca. Essa porcentagem pode ser explicada pelo fato de que $49 \%(\mathrm{~N}=40)$ dos respondentes indicaram que as escolas em que atuam têm um profissional responsável pelo espaço.

Ainda com relação ao planejamento das aulas quando das atividades realizadas na brinquedoteca, o estudo aponta algumas falas que expressam o cotidiano dos professores:

"Após contar histórias para os alunos levo-os para escolherem uma história para levarem para casa e pedir um adulto para contar. É um projeto a 'Mala viajante"' (Depoimento professor).

"As aulas nesse espaço são ministradas pela pessoa responsável e de acordo com o conteúdo que estamos trabalhando. Esse conteúdo é passado previamente para o responsável" (Depoimento professor).

"Atividade para trabalhar noção corporal. As crianças dançam e acompanham um vídeo sobre partes do corpo (cabeça ombro joelho e pé da Xuxa) depois desenham no espelho" (Depoimento professor).

"Minhas aulas são sempre ludicamente auxiliadas por copos coloridos, bolas, bambolês e instrumentos musicais" (Depoimento professor).

Meyer (2008, p. 33) afirma que um planejamento e um bom profissional, proporcionam o desenvolvimento de novas habilidades, bem como a construção de novos conhecimentos.

Segundo Lück (2007, p. 45), “a falta de planejamento para orientar uma ação, ou a sua realização sem os cuidados de análise objetiva e globalizante, tornam-na imprecisa, inconsistente, incoerente e até mesmo inócua", o que pode gerar "uma baixa eficiência e eficácia no trabalho". O planejamento, portanto, é de suma importância tanto para a brinquedoteca quanto para outras ações educacionais.

Persp. Online: hum \& sociais aplicada., Campos dos Goytacazes, 30 (11)1-16- 2021 


\section{CONSIDERAÇÕES FINAIS}

Essa pesquisa teve como objeto de estudo teórico e empírico a compreensão da importância do uso da brinquedoteca como um recurso pedagógico para o desenvolvimento da criança na educação infantil.

A brinquedoteca apresenta-se como um lugar, um espaço de desenvolvimento e aprendizagem que aguça as sensações e emoções das crianças, um lugar de convivência e crescimento pessoal e social.

Durante todo o processo de investigação percebeu-se a partir das falas dos sujeitos da pesquisa - "Seria um sonho!!! A criança poderia brincar, aprender a se comunicar, liberar suas emoções (desejos e sentimentos), desenvolver sua criatividade, adquirir conhecimentos, desenvolver sua autoestima, se socializar num ambiente lúdico" - o reconhecimento da finalidade e importância desse espaço para o desenvolvimento do aluno.

Espera-se, ao final de trabalho, ter contribuído para uma reflexão e compreensão da brinquedoteca enquanto um espaço que proporciona à criança, a vivência e a experimentação a construção de sua aprendizagem e do seu desenvolvimento biopsicossocial. Outro fator a ser destacado é a contribuição desse espaço também para o professor, na medida em que por meio dela, pode-se observar e identificar cada aluno e sua individualidade, além de suas habilidades e dificuldades.

\section{REFERÊNCIAS}

BRASIL. Base Nacional Comum Curricular: documento completo. Brasília: MEC/Secretaria de Educação Básica, 2018. Disponível em: http://basenacionalcomum. mec.gov.br/images/BNCC_EI_EF_110518_versaofinal_site.pdf. Acesso em: 20 abr. 2020.

BRASIL. Conselho Nacional de Educação. Diretrizes Curriculares Nacionais Gerais para a Educação Básica. Resolução $\mathrm{n}^{0}$ 4, de 13 de julho de 2010. Disponível em: http://portal.mec.gov.br/index.php?option $=$ com_docman\&view $=$ download\&alias $=6704$ rceb004-10-1\&category_slug=setembro-2010-pdf\&Itemid=30192. Acesso em: 20 maio 2020 .

BRASIL. Lei de Diretrizes e Bases da Educação Nacional. Lei número 9394, 20 de dezembro de 1996. Estabelece as diretrizes e bases da educação nacional. Disponível em: http://www.planalto.gov.br/ccivil_03/leis/19394.htm. Acesso em: 13 jun. 2020.

BUENO, E. A. B.; FRAGA, J. M. Brinquedoteca: um espaço de desenvolvimento e aprendizagem. Revista da UNIFEBE, [S.1.], v. 1, n. 10 Jan/Jul, jul. 2012.. Disponível em: https://periodicos.unifebe.edu.br/index.php/revistaeletronicadaunifebe/article/view/4. Acesso em: 13 jun. 2020.

CUNHA, N. H. S. Brinquedoteca: um mergulho no brincar. São Paulo: Vetor, 2010.

FONSECA, J. J. S. Metodologia da pesquisa científica. Fortaleza: UEC, 2002.

Persp. Online: hum \& sociais aplicada., Campos dos Goytacazes, 30 (11)1-16- 2021 seer.perspectivasonline.com.br 
FORTUNA, T. R. Por uma brinquedoteca "suficientemente boa" Alguns valores para que as brinquedotecas da América Latina nos encontrem no futuro. In: OLIVEIRA, Vera Barros de. (Org.) Brinquedoteca: uma visão internacional. Petrópolis, RJ: Vozes, 2011. p.162-182.

FROEDE, C.; WOLLZ, L. E. B.; SOUSA, P. M. S.; SOUSA, T. R. S.; MONTEIRO, G. A. Percepções de infâncias e do brincar na contemporaneidade. Perspectivas Online: Humanas \& Sociais Aplicadas, 3(8), 2014. Disponível em: https://ojs3.perspectivasonline.com.br/humanas_sociais_e_aplicadas/article/view/33/19. Acesso em: 20 nov. 2020.

GIL, A. C.. Como elaborar projetos de pesquisa. 5. ed. São Paulo: Atlas, 2010.

LEMOS, Í. A.; MENEZES, A. G. de; ALVES, M. B. N.. A importância da brinquedoteca como ferramenta de ensino aprendizagem. Anais Encontro Internacional de Formação de Professores e Fórum Permanente de Inovação Educacional, v. 9, n. 1, 2016. Disponível em: https://eventos.set.edu.br/ index.php/enfope/article/view /2117/593. Acesso em: 22 maio 2020.

LIMA, L.; DELMONICO, R. Estudo sobre a importância da brinquedoteca no ambiente escolar como espaço mediador de aprendizagens, sob o ponto de vista dos professores da rede municipal de ensino do Cornélio Procópio. 2010. Disponível https://www.pedagogia.com.br/artigos/importanciada

brinquedoteca $1 /$ index.php\#: :text $=\mathrm{O} \% 20$ presente $\% 20$ estudo $\% 20$ caracteriza $\% 2$ Dse,de $\% 20$ Ensino\%20de\%20Corn\%C3\%A91io\%20Proc\%C3\%B3pio. Acesso em: 08 nov. 2020.

LÜCK, H. Planejamento em orientação educacional. 18. ed. Petrópolis, RJ: 2007.

MALUF, A. C. M. Brincar: prazer e aprendizado. 5. ed. Vozes: Petrópolis, 2007.

MEYER, I. C. R. Brincar e viver: projetos em educação infantil. 4. ed. Rio de Janeiro: WAK, 2008.

MORAES, V. M. O brincar na educação infantil e o desenvolvimento da criança. Educationis, v.8, n.1, p.1-7, 2020. Disponível em: https://sustenere.co/index.php/ educationis/article/ view/CBPC2318-3047.2020.001.0001/1897. Acesso em: 22 mar. 2020.

NOFFS. N. de A. A formação de professores em diferentes contextos de aprendizagem. São Paulo: Artgraph, 2016.

OLIVEIRA, Z. R. Educação infantil: fundamentos e métodos. São Paulo: Cortez, 2011.

PETERS, L. L. Brincar para quê? escola é lugar de aprender!: estudo de caso de uma brinquedoteca no contexto escolar. 2009, 286f. Tese (doutorado) - Universidade Federal de Santa Catarina, Centro de Filosofia e Ciências Humanas, Programa de Pós-Graduação em Psicologia, Florianópolis, 2009. Disponível em: https://repositorio.ufsc.br/bitstream/handle/123456789/92692/275057.pdf?sequence=1\&is Allowed=y. Acesso em: 23 jun. 2020.

Persp. Online: hum \& sociais aplicada., Campos dos Goytacazes, 30 (11)1-16- 2021 seer.perspectivasonline.com.br 
PRODANOV, C. C.; FREITAS, E. C. de. Metodologia do trabalho científico: métodos e técnicas da pesquisa e do trabalho acadêmico. [recurso eletrônico]. 2. ed. Novo Hamburgo: Feevale, 2013.

ROSA, F. V. da; KRAVCHYCHYN, H.; VIEIRA, M. L. Brinquedoteca: a valorização do lúdico no cotidiano infantil da pré-escola. Barbaroi, Santa Cruz do Sul, n. 33, p. 827, dez. 2010. Disponível em $<$ http://pepsic.bvsalud.org/scielo.php?script=sci arttext\&pid=S0104-65782010000200002\&lng=pt\&nrm=iso $>$. Acesso em: 16 nov. 2020.

SANTOS, S. M. P. Brinquedoteca: a criança, o adulto e o lúdico. Petrópolis: Vozes, 2000.

SANTOS, S. M. P. dos. Brinquedoteca: sucata vira brinquedo. Porto Alegre: Artes Médicas, 1995.

SOMMERHALDER, A.; ALVES, F.D. Jogo e a educação da infância: muito prazer em aprender. 1. ed. Curitiba, PR:CRV, 2011.

SOUSA, G. S. R. B. de; DAMASCENO, D. P. A importância da brinquedoteca na aprendizagem infantil. In: Anais Fórum Internacional de Pedagogia, IV, 2012, Paraíba. Anais... Campina Grande: Realize Editora, 2012. Disponível em: https://www.editorarealize.com.br/editora/anais/fiped/2012/4584a86a3539cd9e1930286ea 5397579_1577.pdf. Acesso em: 26 jun. 2020.

VERGARA, S. C. Projetos e relatórios de pesquisa em administração. 3. ed. São Paulo: Atlas, 2000.

VYGOTSKY, L. S. Formação social da mente. São Paulo: Martins Fontes, 2007. 